\title{
Mechanical behavior of recycled coarse aggregate concrete reinforced with steel fibers under direct shear
}

\author{
Danying Gao ${ }^{\mathrm{a}, \mathrm{b}}$, Lijuan Zhang ${ }^{\mathrm{a}, \mathrm{c}, *}$, Michelle Nokken ${ }^{\mathrm{c}}$ \\ ${ }^{a}$ Research Center of New Style Building \& Structure, Zhengzhou University, No.100, Kexue Road, Zhengzhou, \\ Henan, China, 450001 \\ ${ }^{b}$ Henan University of Engineering, No.1, Xianghe Road, Zhengzhou, Henan, China, 451191 \\ ${ }^{c}$ Faculty of Engineering and Computer Science, Concordia University, 1455 de Maisonneuve, West, Montreal, \\ Quebec H3G1M8
}

\begin{abstract}
Recycled coarse aggregate (RCA) concrete has attracted more and more attention worldwide in recent years due to the exhaustion of natural coarse aggregate and environmental pollution from construction and demolition waste in civil engineering. In this study, experiments were carried out on over 100 specimens to investigate the mechanical properties and failure mode of concrete with different volume content of steel fibers $(0 \%, 0.5 \%, 1 \%, 1.5 \%$, and $2 \%)$ and different RCA replacement ratio $(0 \%, 30 \%, 50 \%$ and $100 \%)$ under direct shear load. The results show that addition of steel fibers can effectively improve the shear strength and shear toughness of RCA concrete. For a given compressive strength, the RCA replacement ratio has negligible impact on shear strength, but shear deformation and toughness increase as RCA replacement ratio reaches above a 'limiting value'. A shear strength formula for steel fiber reinforced RCA concrete (SFRCAC) based on compressive strength and characteristic coefficient of steel fiber has been put forward.
\end{abstract}

Keywords: Recycled coarse aggregates; Steel fibers; Direct shear; Shear strength; Shear toughness;

\footnotetext{
*Corresponding author, Tel: +8613653818353

E-mail address: gdy@zzu.edu.cn( D. Gao), floycn526@163.com (L. Zhang), m.nokken@concordia.ca (M.Nokken)
} 


\section{Introduction}

Recycling construction and demolition waste is expected to contribute to solving the issue of lack of raw materials, and would allow the construction of infrastructures using a circulatory system for resources[1,2]. Recently, the demand for utilization of waste concrete become more urgent since a great amount of waste concrete produced by natural disasters, such as the Wenchuan earthquake has led to serious environmental problems in China[3, 4]. Available studies have demonstrated that the recycled coarse aggregate ( $\mathrm{RCA}$ ) concrete is a potential solution to minimizing the consumption of natural resources, and utilizes the waste concrete stemming from construction demolition and natural disaster[5-7]. However, most utilization of waste concrete is limited to nonstructural applications such as aggregates in roadway sub-base due to its lower strength, reduced Young's modulus and increased deformation when incorporated into new concrete[8-11].

It has been agreed that steel fibers can improve the mechanical properties of natural coarse aggregate (NCA) concrete, such as tensile strength, toughness, fatigue life, and impact resistance[12, 13]. The positive effect of steel fibers can make up for the shortcomings inherent in the use of RCA and improve the quality of RCA concrete. Adding steel fibers to RCA concrete can prevent and reduce the development of inherent micro-defects in concrete, thus making it feasible to obtain a sound material for structural applications in civil engineering[14-16]. Following this line, Carneiro et al. investigated the influence of steel fibers content $(0.75 \%)$ on the stress-strain behavior of concrete made with $25 \%$ (by volume) RCA and found the addition of 
steel fibers and RCA could both increase the mechanical strength and modify the fracture process[17]. With the addition of steel fibers, the toughness of the RCA concrete was increased and its behavior under compression became similar to that of steel fiber reinforced NCA concrete. As well, the cost savings were significant for an optimum combination of RCA and steel fibers due to quantified environmental benefits of RCA[18]. Therefore, steel fiber reinforced RCA concrete (SFRCAC) has great potential for application in structural members if a balance between steel fiber content and RCA replacement ratio could be achieved for optimal mechanical performance. This will greatly promote the use of RCA in structural applications. However, there is very limited information concerning the coupling effect of RCA replacement and steel fiber content on the mechanical characteristics of concrete under direct shear[19, 20].

In this study, a series of experiments was carried out to investigate the mechanical properties of SFRCAC under direct shear. The objective of this study is (1) to evaluate the shear strength of concrete with different RCA replacement ratio and steel fiber content; (2) to quantify the coupling effect of RCA replacement and steel fiber content on the deformation of concrete in direct shear; and (3) to characterize the crack pattern of SFRCAC specimens under direct shear. This paper, to the best of the authors' knowledge, is the first systematic study focusing on the coupling effect of steel fibers and RCA on the shear strength and deformation of concrete at present, which will be of significance for engineering practice and will provide a necessary data base for the design methodology of RCA concrete structures. 


\section{Experimental Program}

\subsection{Materials}

Portland cement (P.O 42.5) was used in all mixtures. The coarse aggregate included nature coarse aggregate (NCA) and recycled coarse aggregate (RCA). RCA was waste commercial ready-mixed concrete obtained from a concrete testing station. The waste concrete was crushed in a jaw crusher, and sieved to $20 \mathrm{~mm}$ maximum size. The NCA was crushed limestone with the same maximum size of $20 \mathrm{~mm}$. Particle size distribution of coarse aggregates are shown in Fig.1, all satisfied the ASTM-C33 limitation [21]. Table 1 shows the properties of RCA and NCA measured from test in this study. Compared to NCA, RCA had lower specific gravity, higher water absorption and higher porosity as expected due to the cement paste present. According to Chinese Standard [22], where RCA are classified into three categories, in which category I is the best, and can be used as NCA. RCA used in this test is belong to category $\mathbb{I}$, which is in the middle level and is recommended for use in concrete compressive strength below $40 \mathrm{MPa}$. The fine aggregate was river sand with a fineness modulus of 2.67 and apparent density of $2556 \mathrm{~kg} / \mathrm{m}^{3}$. The water reducing agent was polycarboxylate superplasticizer, with the dosage being about $1 \%$ of cement weight and the water-reducing ratio being $25 \%$. The plasticizer was used to ensure that all the concrete mixtures had the similar slump. The coarse aggregate used was in its air-dry condition. The steel fibers used in this study were hooked at both ends with a tensile strength of $1000 \mathrm{MPa}$, a mean diameter $\left(d_{f}\right)$ of $0.559 \mathrm{~mm}$, a mean length $\left(l_{f}\right)$ of $30.5 \mathrm{~mm}$, and an aspect ratio $\left(l_{f} / d_{f}\right)$ of 54.6. 


\subsection{Test Parameters and Mixture Proportions}

RCA replacement rate $\left(r_{g}\right)$, defined as the percentage of RCA in overall coarse aggregate by weight, steel fiber volume content $\left(V_{f}\right)$, and concrete cube compressive strength $\left(f_{c u}\right)$ were the main parameters used in this study. According to the regulations 5.3.2 in Chinese Standard JGJ/T 240-2011[23], for RCA belonging to category $\mathbb{I}$, the standard deviation used in RCAC mixture design can take the same value of NCAC when the RCA replacement ratio is below $30 \%$, and the RCA replacement should be blow $50 \%$. Since the final aim is to use RCA instead of NCA in structural element, based on these considerations, this research investigates $r_{g}$ as $0 \%, 30 \%, 50 \%$, and $100 \%$. The common volume content of steel fibers added into concrete is typically up to $2 \%$, when viewed from the cost and workability performance; the volume ratio of steel fibers $V_{f}$ in this research was taken as 0 , $0.5 \%, 1 \%, 1.5 \%, 2 \%$. As $30 \mathrm{MPa}-60 \mathrm{MPa}$ respectively are the common concrete grades currently used in structural elements in China, so $f_{c u}$ was taken as $30,45,60$ MPa.

Mixture design of SFRCAC were based on target compressive strength ( $f_{c u}=30 \mathrm{MPa}$, $45 \mathrm{MPa}, 60 \mathrm{MPa})$ and target slump $(50 \mathrm{~mm})$, a new mixture design method was used here[24], where water-cement ratio and water content were changed to ensure that ten groups of SFRCAC achieved the target compressive strength and slump with different $r_{g}$ and $V_{f}$. The concrete mixture proportions of the 10 groups are listed in Table 2.

\subsection{Specimen Preparation}

Concrete was mixed using a shaft mixer. First, all aggregates and steel fibers were mixed for 2 minutes to ensure the steel fibers were well dispersed. Then cement was 
added and mixed for another minute. Finally, water and water reducing agent were added to the mixer, and mixed for another 2 minutes. No segregation or bleeding of concrete or balling of steel fibers was observed in any of ten mixtures in this study.

The slump of fresh concrete was tested right after the mixing process. For each mixture, six $150 \mathrm{~mm} \times 150 \mathrm{~mm} \times 150 \mathrm{~mm}$ cubic specimens were cast for compressive strength $\left(f_{c u}\right)$ and splitting tensile strength $\left(f_{t s}\right)$, six $150 \mathrm{~mm} \times 150 \mathrm{~mm} \times 300 \mathrm{~mm}$ prism specimens were cast for elastic modulus $\left(E_{c}\right)$, four $100 \mathrm{~mm} \times 100 \mathrm{~mm} \times 300$ mm prism specimens were cast for shear strength $\left(f_{f v}\right)$ and shear deformation. The specimens were cast in steel moulds, and compacted on a vibration table. The specimens were demoulded after 24 hours and cured in a moisture room at approximately $95 \%$ relative humidity $(\mathrm{RH})$ and $20^{\circ} \mathrm{C}$. The tests were performed at the age of 28 days.

\subsection{Test Procedures}

The specimens were tested on a servo-hydraulic closed-loop testing machine with a capacity of $3000 \mathrm{kN}$. All test methods conducted the China Standard [25]. Firstly, three $150 \mathrm{~mm} \times 150 \mathrm{~mm} \times 150 \mathrm{~mm}$ cube specimens were tested at a loading rate of 0.6 $\mathrm{MPa} / \mathrm{s}$ to failure to obtain the cube compressive strength $\left(f_{c u}\right)$. Six $150 \mathrm{~mm} \times 150$ $\mathrm{mm} \times 300 \mathrm{~mm}$ prism specimens were tested for elastic modulus $\left(E_{c}\right)$ following Chinese Standard GB/T50081 [26], $E_{c}$ is the secant modulus calculated at stress from $0.5 \mathrm{MPa}$ to $0.4 f_{c}$. Three $150 \mathrm{~mm} \times 150 \mathrm{~mm} \times 150 \mathrm{~mm}$ cube specimens were tested for splitting tensile strength $\left(f_{t s}\right)$ with a loading rate of $0.06 \mathrm{MPa} / \mathrm{s}$. The splitting tensile strength was calculated by Equation1. 


$$
f_{t s}=0.637 \times F_{\max } / A
$$

Where $F_{\max }$ is the peak load, N; $A$ is the splitting surface area. The mean value of three test results was recorded as $f_{t s}, \mathrm{MPa}$.

The shear test setup is shown in Fig.2. Two linear variable displacement transducers (LVDTs) were employed on the specimen to measure the relative deformations between the two shear sections. The load was recorded with a load transducer. The ultimate shear strength was calculated as following:

$$
f_{f v}=P_{\max } / 2 b_{e f f} d_{e f f}
$$

Where $f_{f v}$ is the ultimate shear strength, MPa; $P_{\max }$ is the peak shear load, N; $b_{\text {eff }}$ is the effective width of the specimen, that is the average value of the width of the two shear sections), mm; and $d_{\text {eff }}$ is its effective depth, that is the average value of the depth of the two shear sections), mm. At least four specimens in each group were tested and their average ultimate shear strength values are presented in the following sections.

\section{Test Results and Analysis}

\subsection{Load-deformation curves}

The shear load-deformation curves of SFRCAC obtained from the tests are shown in Fig.3.

Figure 3(a) shows the load-deformation curves of SFRCAC with different compressive strength ( $f_{c u}=30.7 \mathrm{MPa}, 46.8 \mathrm{MPa}$ and $62.3 \mathrm{MPa}$, respectively), where $r_{g}=50 \%$ and $V_{f}=1 \%$. Overall, the peak load and critical deformation corresponding 
to peak load increase with the increase of compressive strength. The load-deformation curves of C30R50F1 and C45R50F1 are similar, but the ascending branch of load-deformation curve for C60R50F1 has slight difference which is mainly reflected in the higher deformation in the first loading stage (load below $40 \mathrm{kN}$ ) than the other two curves for C30R50F1 and C45R50F1. The transition zone near peak load on load-deformation curve is wider at the lower strength. The descending branches of C45R50F1 and C60R50F1 are nearly parallel, which means they have similar properties after shear failure. However, C30R50F1 presents an obvious "weakening" which is mainly display by the steeper slope of descending branch- after the transition stage. In this case, the compressive strength of concrete is too low for the steel fibers to give good reinforcement effect as in C45R50F1 and C60R50F1.

The shear load-deformation curves of SFRCAC with different RCA replacement ratio $\left(r_{g}\right)$ are shown in Figure 3(b), where $V_{f}=1 \%$. It can be seen that the four curves are very close, in which the peak load has a slight decrease and critical deformation has a slight increase as $r_{g}$ increases from 0 to $100 \%$, so the reinforcing effect of steel fibers on shear behavior of RCAC is similar with that of NCAC. This phenomenon is different from the previously published results that shear strength had decreasing trend with the increase of RCA replacement ratio [27]. There are probably two reasons which can explain these results: one reason is that the water-cement ratio used here was slightly reduced with the increase of RCA replacement ratio to ensure these four groups specimens had similar compressive strength; the other reason is that specimens in this paper are reinforced by steel fibers, steel fiber can provide the 
bridging effect to prevent the micro-crack expansion, especially can improve the shear strength and corresponding deformation of concrete.

The shear load-deformation curves of SFRCAC with different precentages of steel fibers contents are shown in Figure 3(c), where, $r_{g}=50 \%$ and $f_{c u}$ is approximately $45 \mathrm{MPa}$. It can be seen that both peak load and critical deformation increase significantly with the increase of steel fiber content. These five ascending branches are nearly overlap. The transition zones near the peak load are more wide with the increase of steel fiber content as the steel fibers can provide a larger bridging effect to prevent its crack propagation. After peak load, the load drops dramatically for C45R50F0 without steel fiber, while the load drops obviously slower for other four specimens with steel fibers. The slopes of the descending branch are nearly parallel with different steel fiber content. This indicates that the crack resisting effect of steel fibers on deformation does not increase with the increase of fiber content after shear failure. This may be because the shear resistance of SFRCAC may be mainly provided by concrete matrix rather than and the steel fibers after shear failure.

\subsection{Shear strength}

The cube compressive strength $\left(f_{c u}\right)$, splitting tensile strength $\left(f_{t s}\right)$, and shear strength $\left(f_{f v}\right)$ of SFRCAC are shown in Table 3. When $r_{g}=50 \%$ and $V_{f}=1 \%, f_{f v}$ and $f_{t s}$ increases with the increase of $f_{c u}$, this is consistent with the previously published conclusion that to improve the shear strength, the first way consists on the increase of the compressive strength of the concrete [16]. However, as $f_{c u}$ increases from 34.7 MPa to 62.3 $\mathrm{MPa}, f_{f v} / f_{c u}$ decreases; $f_{f v} / f_{t s}$ decreases slightly. The 
same trend can be found in the research for natural aggregate concrete, where $V_{f}=1 \%$ [28]. Although shear strength of SFRCAC has the same increasing trend as with compressive strength increasing, the increase in the ratio decreases. This is related to the fact that the brittleness of concrete increases with compressive strength, so the $f_{f v} / f_{c u}$ has obvious decreased compared with $f_{f v} / f_{t s}$, which only has slight decrease.

As the RCA replacement ratio $\left(r_{g}\right)$ increases from 0 to $100 \%$, where $V_{f}=1 \%$, the shear strength $f_{f v}$ decreases from 12.8 MPa to $11.7 \mathrm{MPa}$, only a very slight decrease of 1.1 MPa. This is different from many previous conclusions that shear strength declines with the increase of the RCA replacement rate[20, 27, 29]. However, these conclusions were drawn based on the same mixture proportion, where the compressive strength, tensile strength and shear strength of concrete generally decrease with the increase of RCA replacement ratio in this case. In this paper, our study was based on target compressive strength, although $r_{g}$ increases from 0 to $100 \%$, these specimens have similar compressive strength of about $45 \mathrm{MPa}$. This indicates that when SFRCAC has similar compressive strength and same steel fiber content, RCA replacement ratio has a slight effect on the shear strength, which is presented clearly in Fig.4(a), where the ratios of shear strength to compressive strength originating from this paper and other related literature are plotted with different RCA replacement ratios [29-31]. Although the mixture proportions and experimental methods from these sources vary, $f_{f v} / f_{c u}$ from same literature present results in a range with nearly a straight line parallel to $\mathrm{X}$ axis with $r_{g}$ increases from 
0 to $100 \%$. This indicates that the RCA has consistent influence on the shear strength and compressive strength of concrete. But the values of $f_{f v} / f_{c u}$ from this test are much higher than others, likely due to the $1 \%$ volume ratio steel fibers used here. The steel fiber reinforcement effect on shear strength is much larger than that on compressive strength.

Test results from Table. 3 show that, when $r_{g}=50 \%, V_{f}$ increases from 0 to $2 \%$, $f_{f v}$ rises from $6.2 \mathrm{MPa}$ to $14.6 \mathrm{MPa}$, increasing by $135 \%$; the steel fiber has significant reinforcing effect on the shear strength of SFRCAC. The relationship between $f_{f v} / f_{c u}$ and $V_{f}$ is shown in Figure $4(\mathrm{~b})$, in which the test data originate from this paper and previous literature $[16,32,33]$, the compressive strength $f_{c}^{\prime}$ from other literatures had been multiplied by the corresponding adjustment coefficient 1.25 to convert to $f_{c u}$ [34]. From Fig.4 (b), it can be seen that $f_{f v} / f_{c u}$ is roughly proportional to steel fiber content when $V_{f}$ is below $1.5 \%$. The increasing trend of $f_{f v} / f_{c u}$ is distinctly weakens when $V_{f}$ is above $1.5 \%$. This may be due to the higher $V_{f}$ may easily cause the uneven distribution of steel fibers, which will lead to the lower bonding strength between steel fibers and concrete matrix, and also produce some weak regions where no steel fibers. So an optimum steel fiber volume content exists for a given RCAC, beyond which the reinforcing effect of steel fiber on the shear strength becomes weakened with the increase of steel fiber volume content.

Moreover, $f_{f v} / f_{c u}$ also increases with the larger aspect ratio $l_{f} / d_{f}$ in Fig.4(b). This is because the larger the aspect ratio, the higher of bonding strength between the steel fiber and concrete, which can more efficiently prevent shear crack propagation. 
Taking into account the reinforcing effects of $V_{f}$ and $l_{f} / d_{f}$ on shear strength of SFRC, the characteristic coefficient of steel fiber $\lambda_{f}=V_{f} l_{f} / d_{f}$ is regarded as one variable defined as the steel fiber parameter to represent the reinforcing effect of the steel fibers on the composite.

In order to analyze the reinforcing effect of steel fibers on shear strength of RCAC, the relationship between the shear strength increase ratio $\left(f_{f v} / f_{v}\right)$ and characteristic coefficient of steel fiber $\left(\lambda_{f}\right)$ is shown in Fig.5 . The shear strength increase ratio is the ratio between shear strength of SFRCAC $\left(f_{f v}\right)$ to shear strength of RCAC $\left(f_{v}\right)$ with the same mixture proportions except for steel fiber content. Based on the experimental results and other published results, an empirical formula is suggested for predicting the shear strength of SFRCAC as follows.

$$
f_{f v} / f_{v}=1+1.3 \lambda_{f}
$$

According to above analysis, when $V_{f}$ is constant, $f_{f v} / f_{c u}$ is nearly a fixed value with different $r_{g}$, so the calculation model between shear strength and compressive strength for common concrete where $V_{f}=0$ and $r_{g}=0$ has been found to be $f_{v}=0.8 f_{c u}^{0.55}[33]$. Therefore, the relationship between compressive strength and shear strength of SFRCAC can be expressed as Equation (4):

$$
f_{f v}=0.8 f_{c u}^{0.55}\left(1+1.3 \lambda_{f}\right)
$$

Shear strength calculated by Eq.4 is listed in Table 3 to compare with that by test result. The comparison from the table indicates that the calculation results agree well with test data, except the data of C45R50F2. According to the previous analysis, when 
$V_{f}$ is larger than $1.5 \%$, the enhancement effect of steel fiber becomes weak, but the calculation by Eq. 4 can't reflect this character, so when $V_{f}$ is $2 \%$, the calculated value is larger than the test value. Further research should be taken for SFRCAC with steel fiber content above $2 \%$.

\subsection{Shear toughness}

The concept of toughness indicates the ability of energy absorption. In the present work, the bending toughness is often determined using the ASTMC1609-12 test methods since they are the most widely used and reported methods for characterizing fiber-reinforced concrete behavior. This test provides the determination of specimen toughness based on the area under the load-deflection curve up to a prescribed deflection[35]. In order to evaluate the energy absorption ability of SFRCAC under direct shear, the area under shear load-deformation curves from initial point to peak point is calculated, which is defined as the shear fracture energy $\left(W_{f v}\right)$; a similar method had been used in previous literature [32], The shear toughness index $\left(K_{v}\right)$ is defined as shear fracture energy per unit compressive strength of concrete as Equation(5):

$$
K_{v}=W_{f v} / f_{c u}
$$

Where, $K_{v}$ is shear toughness index; $W_{f v}$ is shear fracture energy, $\mathbf{J} ; f_{c u}$ is compressive strength, MPa; Calculated values of $K_{v}$ for SFRCAC in this paper are shown in Fig.6.

In general, addition of steel fibers can dramatically improve the toughness of RCA 
concrete and the steel fiber volume fraction $V_{f}$ has important impact on shear toughness. When $V_{f}=2 \%$, the shear toughness index increases as much as four times compared to that without steel fibers. However, the increase of toughness index is not linear with increase of $V_{f}$ but has a significant increase when $V_{f}$ increases from $0.5 \%$ to $1 \%$, when $V_{f}$ is below $0.5 \%$, the reinforcing effect of steel fiber on toughness is not apparent. This may be due to the fact that there are many inherent small cracks in RCA, and there is too low steel fiber content to prevent the crack extension. In order to improve the shear toughness of RCAC, $V_{f}$ should be greater than $0.5 \%$.

The relationship between shear toughness index and RCA replacement ratio displays interesting "two platforms" phenomenon. When $r_{g}$ increases from $0 \%$ to $30 \%$, the shear toughness index is nearly constant, then it has an obvious increase as $r_{g}$ increases from $30 \%$ to $50 \%$, after that it continues to keep constant when $r_{g}$ increases from $50 \%$ to $100 \%$. There are many related results about the impact of the RCA replacement ratio on the property of RCAC: such as, medium compressive strength concrete made with $25 \%$ of recycled coarse aggregates achieved the same mechanical properties as that of conventional concrete employing the same quantity of cement and the equal effective w/c ratio [8]; in other research, not much significant difference is observed in compressive strength of RAC up to $50 \%$ replacement of coarse aggregate [36]. In Chinese Standards, when RCA replacement ratio is less than $30 \%$, the standard deviation of strength used in the mixture design can take the same value with NCA concrete[23]. Analysing all these conclusions mentioned above, one 
regulation can be summarized: there is a limit of $r_{g}$ value for a given strength of RCAC, when $r_{g}$ is below a limit value RCAC can achieve same mechanical properties as that of NCAC, this limit value is affected by the property of RCA.

Overall, shear toughness index of RCAC has no decrease with the increase of $r_{g}$, this conclusion is different from many other literatures [37-39], where the property of RCAC decreased with the rising of $r_{g}$ because the same mixture design method of NCAN and RCAC were used in these studies and which lead to RCAC has lower compressive strength than that of NCAC. However, the four group specimens in this study were reinforced by $1 \%$ steel fiber and had similar $f_{c u}$ and $f_{t s}$, the shear toughness index has same changing trend with the change of elastic modulus.

From Table.3, we know that when $r_{g}=50 \%$ and $V_{f}=1 \%, f_{t s}, f_{f v}$ and $E_{c}$ all increase with the increase of $f_{c u}$ except $K_{v}$. $K_{v}$ has a slight increase when $f_{c u}$ increases from $34.7 \mathrm{MPa}$ to $46.8 \mathrm{MPa}$, and has a marked decrease when $f_{c u}$ increases from 46.8 MPa to $62.3 \mathrm{MPa}$ although $W_{f v}$ is nearly constant. This may be that steel fiber and coarse aggregate have greater impact on shear toughness than compressive strength when compressive strength is above $45 \mathrm{MPa}$. This conclusion can be well explained by the property of RCA, the crushing index of this type of RCA is $17.7 \%$ which may easily cause RCA damage rather than cement matrix damage when compressive strength is above $40 \mathrm{MPa}$, where the damaged RCA can be easily found in shear failure section as shown in Fig.7. So for RCA belonging to category $\mathbb{I}$, although the compressive strength of RCAC may achieve $60 \mathrm{MPa}$ by using lower water-cement ratio, the shear toughness can't be improved effectively. 


\subsection{Failure Mode}

The shear experiment showed that the failure process and crack pattern of SFRCAC specimens were greatly affected by steel fibers. For the specimens without steel fibers, when visible tiny cracks occurred along the shear sections (Fig.2) fracture happened immediately. The specimens lost their integrity and were split into three parts along the shear section after damage. Two typical broken cross sections are shown in Figure 7 , in which each section is corresponding to two photos, the section is smooth just like if cut with a knife. It can be seen clearly that some RCA has been broken on the shear section in Fig.7, this is because the strength of RCA is lower than the strength of cement matrix so that shear cracks go through the RCA directly. There are two weak links in RCA, one is the inherent cracks produced in crushing, another is the stone-mortar interface on RCA. Most of the failure of RCA begins from these weak points. The shear failure of the specimens without steel fibers happens as soon as the cracks appear, and presents complete brittleness.

The specimens with steel fibers exhibits typical ductile failure under shear load. First, a visible fine crack appeared along the shear section. With the load increasing, a number of micro cracks near the first crack increased gradually. Accompanying the extension and connection of these tiny cracks, the surface crack zone formed finally along the shear section. Some steel fibers between the crack zones were pulled out or snapped gradually. Due to the bridging effect of steel fibers between cracks, the specimens still maintained their integrity after failure, but the spalling degree of concrete matrix near the shear failure section is different. The lower the steel fiber 
content, the more concrete spalling.

\section{Conclusions}

The mechanical characteristics of concrete with different RCA replacement ratios and different steel fiber volume content have been experimentally studied through a direct shear test. Based on the extensive test data and analysis, the following conclusions can be drawn:

- The addition of steel fibers can effectively improve the shear strength and shear toughness of RCAC. As the steel fiber volume content increases from 0 to $2 \%$, shear strength of RCAC increases by $135 \%$ and its shear toughness index increases by four times compared to that of RCAC without steel fibers.

- The shear strength and shear brittleness of SFRCAC increase with the increase of its compressive strength. The shear toughness of SFRCAC with category II RCA can't be improved effectively above $45 \mathrm{MPa}$ although the compressive strength may achieve 60MPa by using lower water-cement ratio.

- With the given compressive strength and steel fiber volume content, the RCA replacement ratio has slight effect on shear strength, the relationship between shear strength and compressive strength for NCAC can also be used for RCAC. A shear strength formula for SFRCAC based on compressive strength and characteristic coefficient of steel fiber was put forward.

- When the replacement ratio of RAC belonging to category II is below a limiting value of $30 \%$, the adverse effect of RCA on the shear action of SFRCAC can be 
ignored. With the given strength, the shear deformation increases when RCA replacement ratio is above this limiting value. RCA replacement ratio has similar effect on shear toughness index and the elastic modulus.

- SFRCAC specimens exhibit ductile failure and maintain its integrity after shear failure; however, the specimen without steel fibers exhibits a brittle failure. The reinforcing effect of steel fiber on RCAC is similar with that on NCAC.

\section{Acknowledgments}

The research reported in this paper was partly supported by the National Science Foundation of China under Grant Nos. 51379186 and 51522905, which are gratefully acknowledged. The authors would like to thank Miss Jingyun Lu and Mr. Zhaoqiang for their participation in experimental project. The comments of Dr. Dongming Yan of Zhejiang University are also gratefully acknowledged.

\section{References:}

[1] Marie I, Quiasrawi H. Closed-loop recycling of recycled concrete aggregates. Journal of Cleaner Production. 2012;37:243-8.

[2] Li X. Recycling and reuse of waste concrete in China. Resources, Conservation and Recycling. 2009;53(3):107-12.

[3] Xiao J, Xie H, Zhang C. Investigation on building waste and reclaim in Wenchuan earthquake disaster area. Resources, Conservation and Recycling. 2012;61:109-17.

[4] Xu B, Zou D, Kong X, Hu Z, Zhou Y. Dynamic damage evaluation on the slabs of the concrete faced rockfill dam with the plastic-damage model. Computers and Geotechnics. 2015;65:258-65.

[5] Maier PL, Durham SA. Beneficial use of recycled materials in concrete mixtures. Construction and Building Materials. 2012;29:428-37.

[6] Limbachiya M, Meddah MS, Ouchagour Y. Use of recycled concrete aggregate in fly-ash concrete. Construction and Building Materials. 2011;27:439-49.

[7] Henry M, Kato Y. Sustainable concrete in Asia: Approaches and barriers considering regional context. Construction and Building Materials. 2014;67:399-404.

[8] Etxeberria M, Vázquez E, Marí A, Barra M. Influence of amount of recycled coarse aggregates and production process on properties of recycled aggregate concrete. Cement and Concrete Research. 
2007;37(5):735-42.

[9] Khokhar MIA, Roziere E, Turcry P, Grondin F, Loukili A. Mix design of concrete with high content of mineral additions: Optimisation to improve early age strength. Cement and Concrete Composites. 2010;32(5):377-85.

[10] Meyer C. The greening of the concrete industry. Cement and Concrete Composites. 2009;31(8):601-5.

[11] Casuccio M, Torrijos MC, Giaccio G, Zerbino R. Failure mechanism of recycled aggregate concrete. Construction and Building Materials. 2008;22(7):1500-6.

[12] Shah AA, Ribakov Y. Recent trends in steel fibered high-strength concrete. Materials \& Design. 2011;32(8-9):4122-51.

[13] Lee S-C, Oh J-H, Cho J-Y. Compressive Behavior of Fiber-Reinforced Concrete with End-Hooked Steel Fibers. Materials. 2015;8(4):1442-58.

[14] Erdem S, Dawson AR, Thom NH. Microstructure-linked strength properties and impact response of conventional and recycled concrete reinforced with steel and synthetic macro fibres. Construction and Building Materials. 2011;25(10):4025-36.

[15] Banthia N, Majdzadeh F, Wu J, Bindiganavile V. Fiber synergy in Hybrid Fiber Reinforced Concrete (HyFRC) in flexure and direct shear. Cement and Concrete Composites. 2014;48:91-7.

[16] Boulekbache B, Hamrat $M$, Chemrouk M, Amziane S. Influence of yield stress and compressive strength on direct shear behaviour of steel fibre-reinforced concrete. Construction and Building Materials. 2012;27(1):6-14.

[17] Carneiro JA, Lima PRL, Leite MB, Toledo Filho RD. Compressive stress-strain behavior of steel fiber reinforced-recycled aggregate concrete. Cement and Concrete Composites. 2014;46:65-72.

[18] Senaratne S, Gerace D, Mirza O, Tam VWY, Kang W-H. The costs and benefits of combining recycled aggregate with steel fibres as a sustainable, structural material. Journal of Cleaner Production. 2016;112:2318-27.

[19] Arulrajah A, Disfani MM, Horpibulsuk S, Suksiripattanapong C, Prongmanee N. Physical properties and shear strength responses of recycled construction and demolition materials in unbound pavement base/subbase applications. Construction and Building Materials. 2014;58:245-57.

[20] Ceia F, Raposo J, Guerra M, Júlio E, de Brito J. Shear strength of recycled aggregate concrete to natural aggregate concrete interfaces. Construction and Building Materials. 2016;109:139-45.

[21] ASTM. Standard Specification for Concrete Aggregates. West Conshohocken: ASTM International; 2013.

[22] SCA. GB/T21557-2010, Recycled coarse aggregate for concrete. Beijing: China Standard Press; 2010.

[23] AQSIQ, SAC. Technical specification for application of recycled aggregate ,GJG/T204-2011. Beijing:

Standard Press of China; 2011. p. 10-1.

[24] Gao D, Zhang L, Lu J, Yan Z. Research on Design Parameters of Mix Proportion for Recycled Aggregate Concrete. Journal of Architecture and Civil Engineering. 2016;33(1):8-14.

[25] Standard test methods for fiber reinforced concrete. CECS13, China. Standards China2010. p. 48.

[26] MOC, GAQSIQ. Standard for test method of mechanical properties on o rdinary concrete , GB/T50081,. Beijing: China Architecture \& Building Press 2002. 
[27] Xiao J, Li W, Fan Y, Huang X. An overview of study on recycled aggregate concrete in China (1996-2011). Construction and Building Materials. 2012;31:364-83.

[28] M Yang CH, Y Liu. Experimental research on shear behavior of high-strength SFRC. Journal of Dalian University of Technology. 2005;45(6):842-6.

[29] Wang W-I, Kou S-c, Xing F. Deformation properties and direct shear of medium strength concrete prepared with 100\% recycled coarse aggregates. Construction and Building Materials. 2013;48:187-93.

[30] Rahal K. Mechanical properties of concrete with recycled coarse aggregate. Building and Environment. 2007;42(1):407-15.

[31] Waseem SA, Singh B. Shear transfer strength of normal and high-strength recycled aggregate concrete - An experimental investigation. Construction and Building Materials. 2016;125:29-40.

[32] Appa Rao G, Sreenivasa Rao A. Toughness indices of steel fiber reinforced concrete under mode II loading. Materials and Structures. 2009;42(9):1173-84.

[33] Gao D, Zhu H, Tang J. Shear strength of steel fiber reinforced high-strength concrete. JOURNALOF THE CHINESE CERAMIC SOCIETY. 2005;33(1):82-6.

[34] Guo Z. Principle of Reinforced Concrete. Beijing: Tsinghua University Press; 2013.

[35] ASTM. Standard Test Method for Flexural Performance of Fiber-Reinforced Concrete (Using Beam With Third-Point Loading). West Conshohocken: ASTM International; 2012.

[36] Chakradhara Rao M, Bhattacharyya SK, Barai SV. Influence of field recycled coarse aggregate on properties of concrete. Materials and Structures. 2010;44(1):205-20.

[37] Abdulla NA. Effect of Recycled Coarse Aggregate Type on Concrete. Journal of Materials in Civil Engineering. 2015;27(10):04014273.

[38] Gastaldi D, Canonico F, Capelli L, Buzzi L, Boccaleri E, Irico S. An investigation on the recycling of hydrated cement from concrete demolition waste. Cement and Concrete Composites. 2015;61:29-35.

[39] Huda SB, Shahria Alam M. Mechanical and Freeze-Thaw Durability Properties of Recycled Aggregate Concrete Made with Recycled Coarse Aggregate. Journal of Materials in Civil Engineering. 2015;27(10):04015003. 


\section{List of Table}

\section{Table1.}

Physical properties of coarse aggregate

\begin{tabular}{ccccccc}
\hline Aggregate type & $\begin{array}{c}\mathrm{AD} \\
\left(\mathrm{kg} / \mathrm{m}^{3}\right)\end{array}$ & $\begin{array}{c}\text { LBD } \\
\left(\mathrm{kg} / \mathrm{m}^{3}\right)\end{array}$ & $\begin{array}{c}\text { RBD } \\
\left(\mathrm{kg} / \mathrm{m}^{3}\right)\end{array}$ & $\begin{array}{c}\text { Water absorption } \\
(\mathrm{wt} \%)\end{array}$ & $\begin{array}{c}\text { Crush index } \\
/ \%\end{array}$ & $\begin{array}{c}\text { Porosity } \\
/ \%\end{array}$ \\
\hline NCA & 2814 & 1568 & 1630 & 1.40 & 8.80 & 44.3 \\
RCA & 2640 & 1302 & 1412 & 4.85 & 17.7 & 50.3 \\
\hline
\end{tabular}

AD: Apparent density; LBD: Loose bulk density; RBD: Rodded bulk density.

Table2.

Summary of concrete mixture proportions

\begin{tabular}{lcccccccc}
\hline \multicolumn{1}{c}{ Group } & $\mathrm{w} / \mathrm{c}$ & $\begin{array}{c}\text { Water } \\
\left(\mathrm{kg} / \mathrm{m}^{3}\right)\end{array}$ & $\begin{array}{c}\text { Cement } \\
\left(\mathrm{kg} / \mathrm{m}^{3}\right)\end{array}$ & $\begin{array}{c}\mathrm{NCA} \\
\left(\mathrm{kg} / \mathrm{m}^{3}\right)\end{array}$ & $\begin{array}{c}\mathrm{RCA} \\
\left(\mathrm{kg} / \mathrm{m}^{3}\right)\end{array}$ & $\begin{array}{c}\text { Fine } \\
\text { aggregate } \\
\left(\mathrm{kg} / \mathrm{m}^{3}\right)\end{array}$ & $\begin{array}{c}\text { Steel fiber } \\
\left(\mathrm{kg} / \mathrm{m}^{3}\right)\end{array}$ & $\begin{array}{c}\text { Water } \\
\text { reducer } \\
\left(\mathrm{kg} / \mathrm{m}^{3}\right)\end{array}$ \\
\hline C45R50F0 & 0.39 & 158 & 406.0 & 553.0 & 553.0 & 768.8 & 0 & 4.06 \\
C45R50F0.5 & 0.39 & 164 & 420.5 & 527.3 & 527.3 & 749.0 & 39 & 4.21 \\
C45R50F1 & 0.39 & 170 & 437.0 & 506.0 & 506.0 & 737.0 & 78 & 4.37 \\
C45R50F1.5 & 0.39 & 177 & 453.5 & 506.4 & 506.4 & 753.6 & 117 & 4.54 \\
C45R50F2 & 0.39 & 183 & 469.2 & 472.5 & 472.5 & 724.7 & 156 & 4.69 \\
C45R0F1 & 0.41 & 166 & 405.0 & 1121.4 & 0.0 & 739.8 & 78 & 4.05 \\
C45R30F1 & 0.40 & 169 & 422.0 & 735.0 & 315.0 & 736.6 & 78 & 4.22 \\
C45R100F1 & 0.37 & 175 & 479.4 & 0.0 & 938.0 & 746.5 & 78 & 4.79 \\
C30R50F1 & 0.54 & 170 & 315.0 & 534.0 & 534.0 & 775.8 & 78 & 3.15 \\
C60R50F1 & 0.31 & 170 & 548.4 & 476.0 & 476.0 & 695.3 & 78 & 5.48 \\
\hline
\end{tabular}

Note: C45R50F1: $f_{c u}=45 \mathrm{MPa}, r_{g}=50 \%$ and $V_{f}=1 \%$.

Table 3

Strength, slump and elastic modulus.

\begin{tabular}{lccccccc}
\hline Specimen No. & $\begin{array}{c}\text { Slump } \\
/ \mathrm{mm}\end{array}$ & $\begin{array}{c}\text { Elastic } \\
\text { modulus/GPa }\end{array}$ & $\begin{array}{c}f_{c u} \\
/ \mathrm{MPa}\end{array}$ & $\begin{array}{c}f_{t s} \\
/ \mathrm{MPa}\end{array}$ & $\begin{array}{c}f_{f v}(\text { Test data }) \\
/ \mathrm{MPa}\end{array}$ & $\begin{array}{c}f_{f v} \text { ( Calculated } \\
\text { value }) / \mathrm{MPa}\end{array}$ & $W_{f v} / \mathrm{J}$ \\
\hline C45R50F0 & 55 & 29.7 & 44.9 & 2.77 & 6.2 & 6.5 & 21.3 \\
C45R50F0.5 & 60 & 34 & 45.6 & 4.11 & 9.0 & 9.0 & 27.8 \\
C45R50F1 & 54 & 38.4 & 46.8 & 5.57 & 11.8 & 11.3 & 95.3 \\
C45R50F1.5 & 50 & 41.9 & 48.1 & 7.02 & 13.9 & 13.9 & 101.9 \\
C45R50F2 & 48 & 42.9 & 49.9 & 7.61 & 14.6 & 16.6 & 127.2 \\
C45R0F1 & 62 & 33 & 45.4 & 5.60 & 12.8 & 11.2 & 73.7 \\
C45R30F1 & 60 & 34.6 & 46.0 & 5.53 & 12.2 & 11.2 & 77.5 \\
C45R100F1 & 52 & 37.8 & 47.2 & 5.35 & 11.7 & 11.4 & 92.6 \\
C30R50F1 & 65 & 28.8 & 34.7 & 4.79 & 10.4 & 9.6 & 66.6 \\
C60R50F1 & 52 & 44.2 & 62.3 & 6.72 & 13.5 & 13.3 & 93.4 \\
\hline
\end{tabular}

Note: All strengthes were tested at 28 days. $f_{f v}$ calculated value were calculated by Eq. 4 . 
Figure Captions

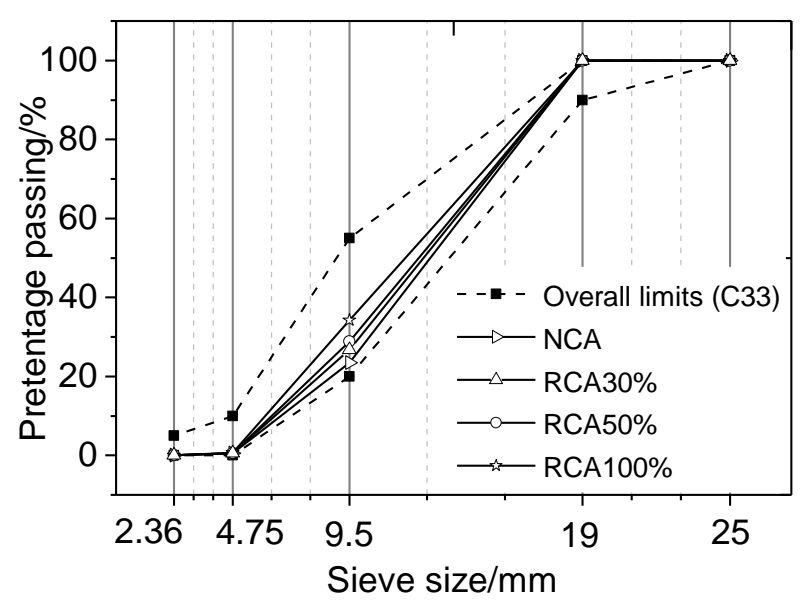

Fig.1. Particle size distribution of coarse aggregates.
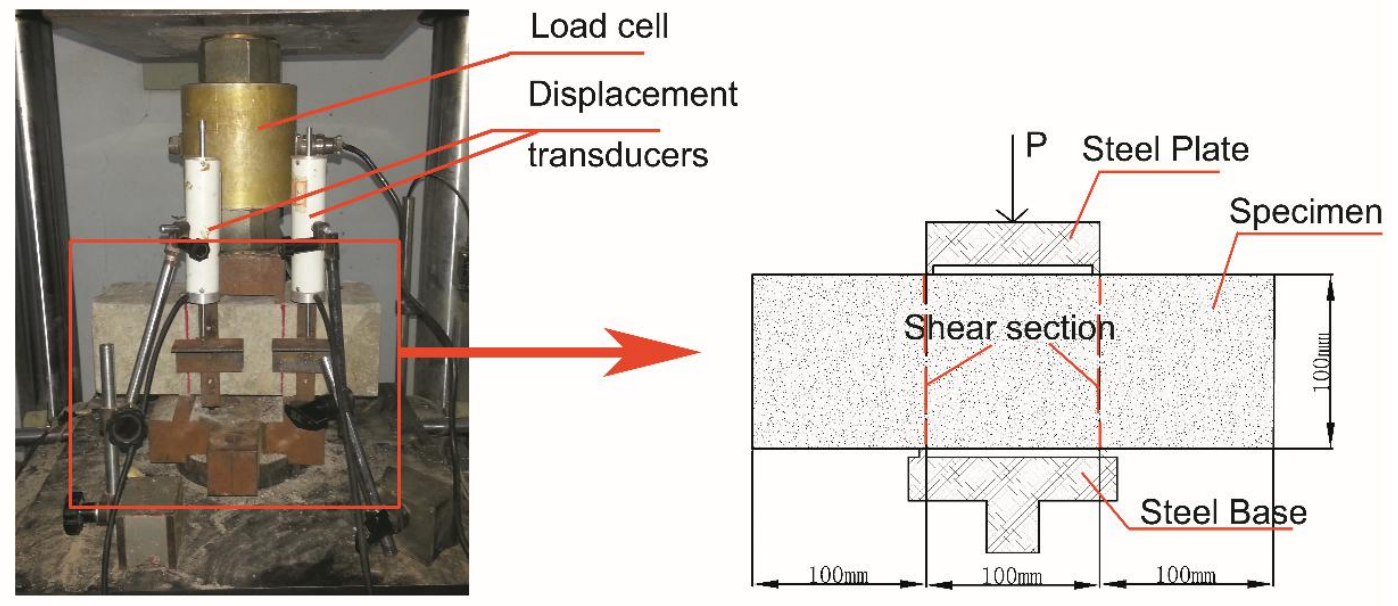

Fig.2. Test setup.

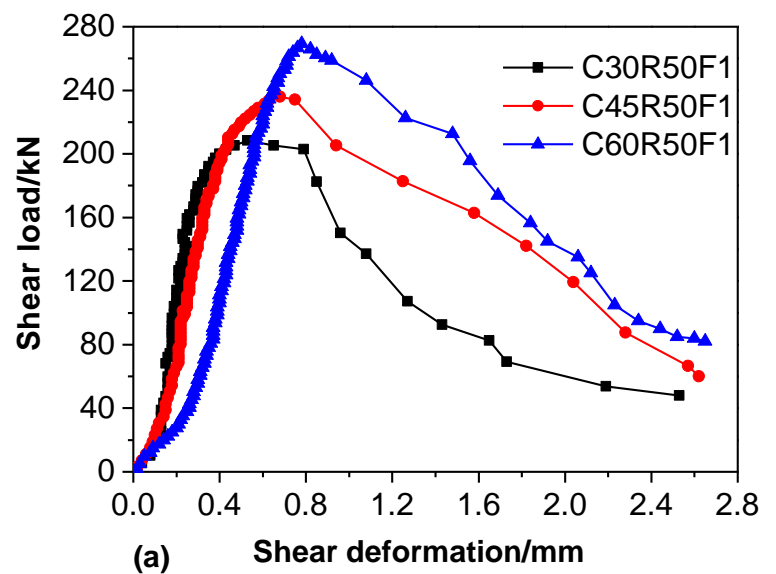




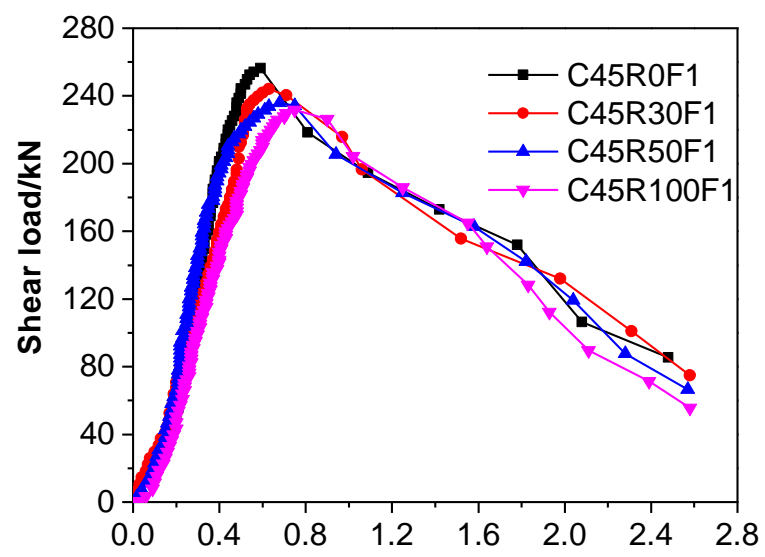

(b) Shear deformation $/ \mathrm{mm}$

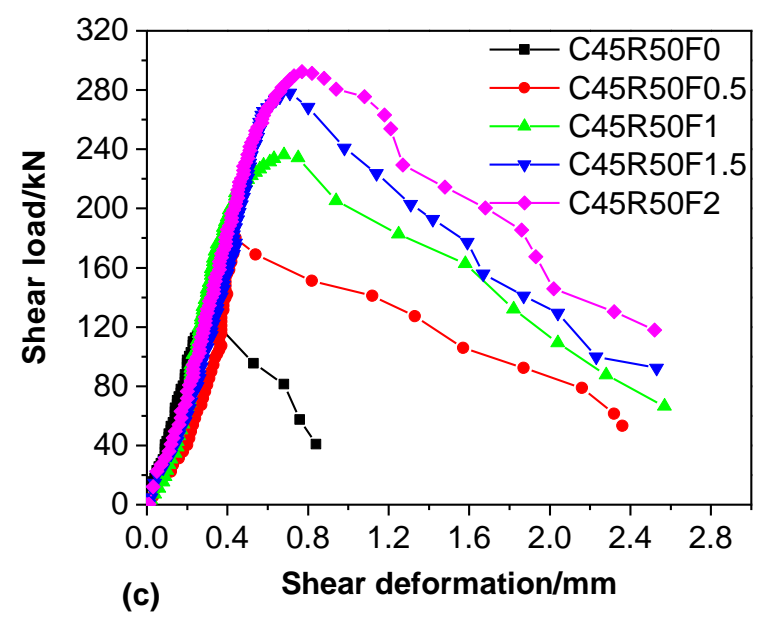

Fig.3 Shear load-deformation curves with different (a) Compressive strength;(b) RCA replacement ratio; (c) Steel fiber content.

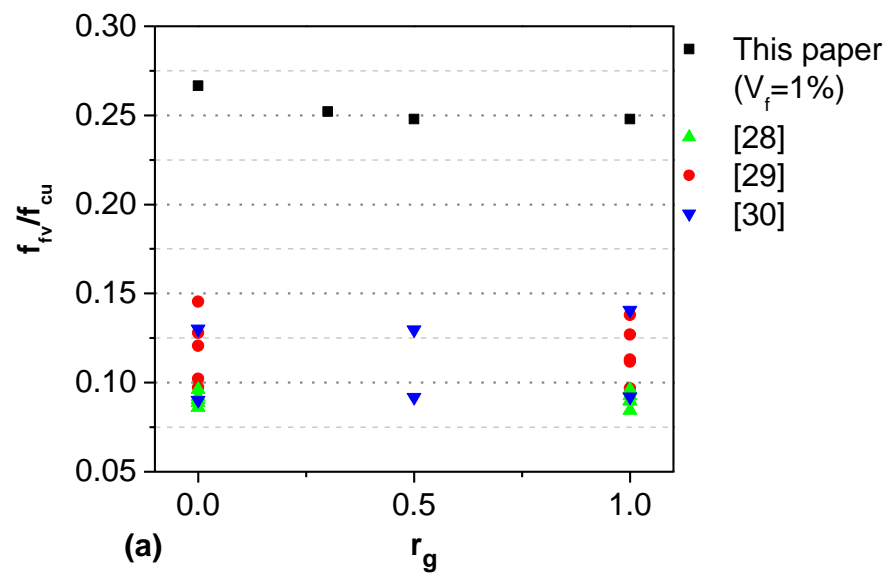




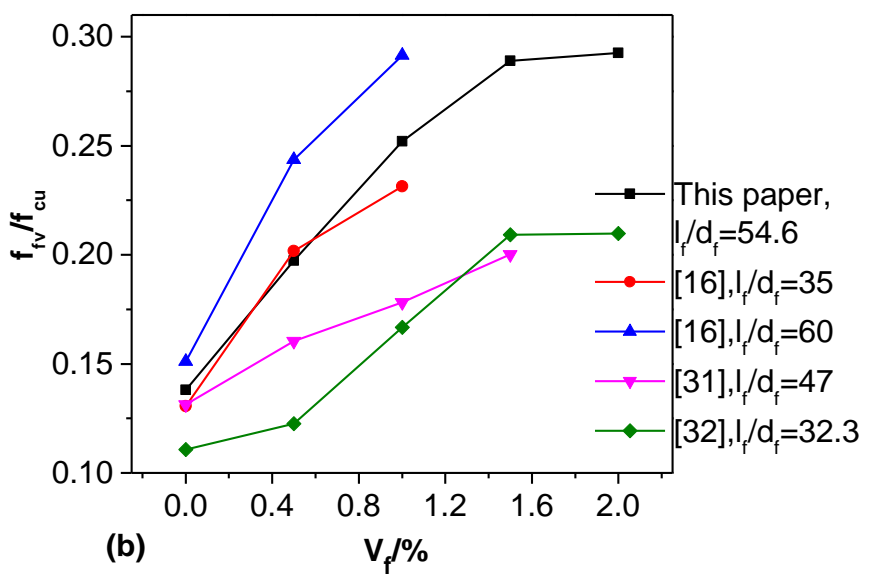

Fig.4 Relationship of $f_{f v} / f_{c u}$ with different (a) $r_{g}$; (b) $V_{f}$.

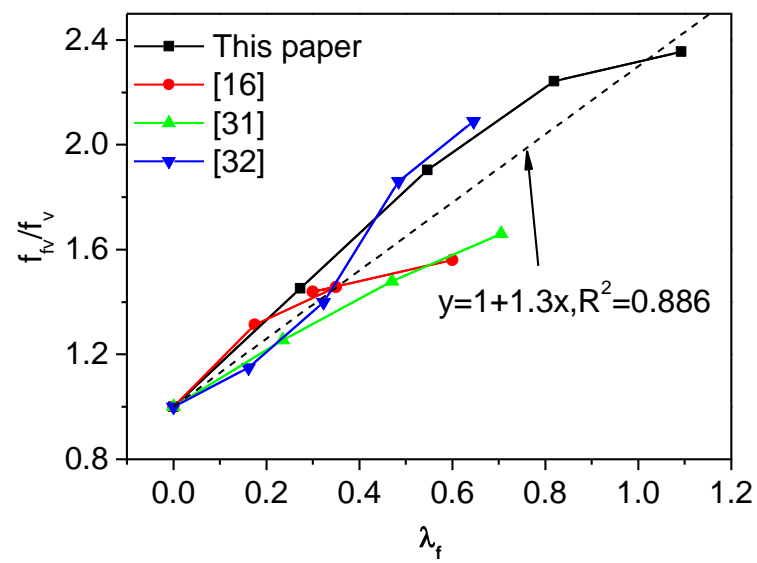

Fig.5 Relationship between $f_{f v} / f_{v}$ and $\lambda_{f}$ 

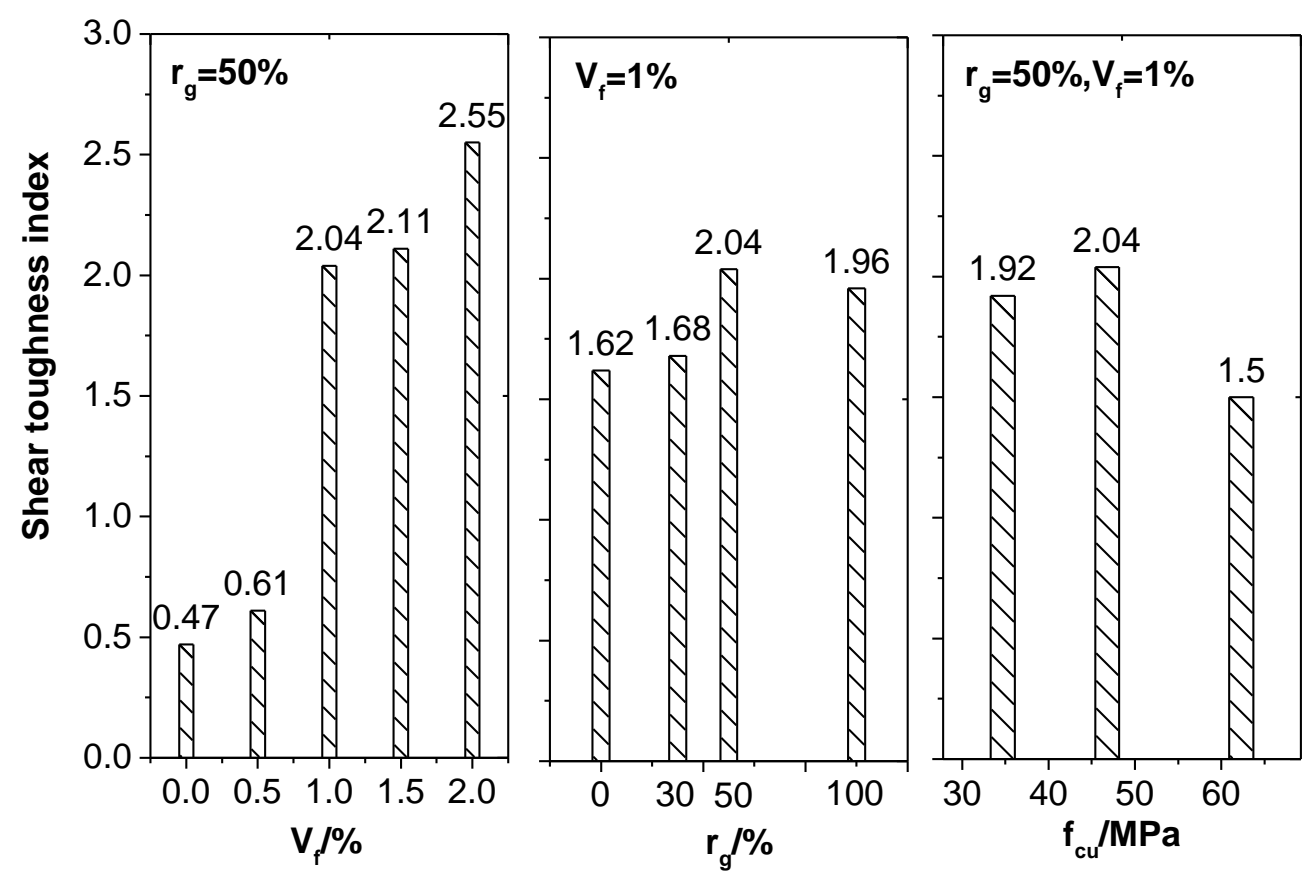

Fig.6 Shear toughness index with different $V_{f}, r_{g}$ and $f_{c u}$

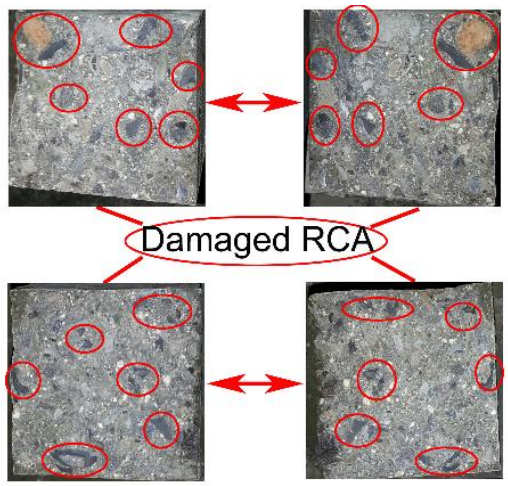

Fig.7 Failure section of specimens without steel fibers. 